\title{
Development of Face Recognition Software to Differentiate Autism Spectrum Disorder from Typical Adolescents
}

\author{
Supra Wimbarti', Willy Kristianto Yappy ${ }^{2}$ \\ ${ }^{1}$ Faculty of Psychology, Universitas Gadjah Mada \\ ${ }^{2}$ Universität des Saarlandes, Germany
}

Submitted 8 October 2020 Accepted 24 November 2020 Published 23 December 2020

\begin{abstract}
The purpose of this research was two folds: (1) to establish the face recognition software; and (2) to differentiate the ability in face recognition between Autism Spectrum Disorder (ASD) from typical adolescents. The subjects were adolescents between 10-16 years old. The experimental group consisted of 31 adolescents with ASD, the control group consisted of 32 typical adolescents. Research was done using experimental method, with face recognition software. Data collected were the number of correct faces recognized and the time needed to recognize and touch the face. The hypothesis was adolescents with ASD have worse face recognition ability compared to typical adolescents. Result showed that there were differences between ASD group compared to normal group both in the number of correct face recognitions and the time needed to choose a face with a finger touch. A one-way MANOVA revealed a significant multivariate main effect for type of groups toward the number of correct answers and time needed to answer, Wilks' $\lambda=0.739, F(2,60)=10.610, p<0.001$. The univariate main effect were also examined, whereupon significant univariate main effect for type of groups were obtained for both the amount of correct answer, $F(1,61)=15.468 p<0.001$, and the amount of time needed to answer, $F(1,61)=21.360 p<0.001$.
\end{abstract}

Keywords: adolescent; autism spectrum disorder; diagnoses; fusiform gyrus; neurodevelopmental disorder

Autism Spectrum Disorder (ASD), also called autism, is a neurodevelopmental disorder. One of the current issues with autism in Indonesia is the problem of common yet misleading information regarding autism. News outlet used this information to create sensational news such as "Beware! Child with Autism can have Mental Health Problems" (Anggraeni, 2017). While, according to DSM-5 (American Psychiatric Association, 2013), there are 5 general criteria and 7

\footnotetext{
${ }^{1}$ Address for correspondence: supra@ugm.ac.id
}

special criteria for diagnosing ASD; such information is not easy to digest by public, leading to many misinterpretations and guessing.

The problem of autism in Indonesia is also compounded by the fact that access to mental health institutions and practitioners is severely limited. There are only 451 clinical psychologists, 773 psychiatrists and 6.500 mental health nurse; while out of 34 provinces in Indonesia, only 26 provinces have access to mental health facilities (Manafe, 2018; 
Lestari, 2016). The limited number of mental health practitioners means that many rural areas are not within reach of mental health services. By reflecting on the implementation of health services in Indonesia, it is found that the tiered health services can be helpful in solving the problem of limited practitioners and health facilities. By using primary health service as model, a primary early detection system for mental health issues should be implemented.

In the case of autism, it is now understood that subjects with autism are using an atypical face viewing strategy, such as not fixating on the eyes (Golarai, Grill-Spector, \& Reiss, 2006). Additional researches in face recognition found that children with autism show profound deficit in the active voxels in the fusiform bilaterally as much as $25 \%$ of typically developing children (Pierce \& Redcay, 2008), show delay and reduced amplitudes in all early potentials in ERP in all face stimulus (Apicella, Sicca, Federico, Campatelli, \& Muratori, 2013) and behaviorally, children with autism show unusual significant preoccupation to the mouth region when processing information from people's faces (Joseph \& Tanaka, 2003).

Current screening process for ASD, involves checklist, like in M-CHAT, to be filled by the parents/teacher (Kleinman et al., 2008) or rating scale such as CARS (Schopler, Van Bourgondien, Wellman, \& Love, 2010) and ASSQ (Ehlers, Gillberg, \& Wing, 1999). Since most screenings involve scales filled by parents, teachers, or observers, the subjective nature of observation might skew the data, and as such, method involving direct input from the autistic children should be preferable.

Face recognition is affected by many factors, such as pigmentation or skin color (Russell, Sinha, Biederman, \& Nederhouser, 2006) holistic representation of face (Zhang, Li, Song, \& Liu, 2012), race familiarity (Tanaka, Kiefer, \& Bukach, 2004), and gender (Connellan, BaronCohen, Wheelwright, Batki, \& Ahluwalia, 2000). In children with ASD, it is known that the face recognition process depended the mouth region, while showing weak performance when the recognition depended on the eyes (Joseph \& Tanaka, 2003). Neurologically, researches focused on brain volume showed significant decrease in neuron densities in layer III, total neuron numbers in layers III, V, and $\mathrm{VI}$, and mean perikaryal volumes of neurons in layers V and VI in the Fusiform Gyrus (van Kooten et al., 2008). Regarding activities, fusiform gyrus in children with autism show different responses depending on the face object they see. Fusiform gyrus is active when seeing the faces of mother or other children, while showing decrease in activation bilaterally around $25 \%$ when seeing adults with unknown faces (Pierce \& Redcay, 2008).

Interest and attention seem to be important factors that affect the activation of fusiform gyrus in children, as finding by Grelotti et al. (2005) showedactivities of amygdala and fusiform gyrus when seeing Digimon (digital monster), but such activation did not happened when seeing familiar or unfamiliar faces. It should be noted that such activation were not found in control. 
Purpose and research hypothesis

The purpose of this research was to (1) to establish the face recognition software, and as such, can be used to escalate further diagnosis, for the usage of early detection process in primary health care facilities; and (2) to differentiate the ability in face recognition between ASD adolescents from typical adolescents. The software developed was then designed to test the face recognition ability to test two research hypotheses, those are: Research Hypothesis 1: adolescents with autism spectrum disorder have different face recognition ability compared to typical adolescents. Research Hypothesis 2: worse performance in face recognition ability in ASD adolescents is shown in less correct answers and longer average time needed to answer in face recognition test compared to typical adolescents.

\section{Methods}

\section{Study 1: Developing the software}

The instruments used in this study consisted of two parts: hardware and software. The hardware, which was Toshiba Satellite E45W-C4200X laptop, equipped with Intel ${ }^{\circledR}$ Core $^{\mathrm{TM}}$ i3-5015U Processor, clocked at $2.1 \mathrm{Ghz}$, with 4 GB of DDR3L RAM, and 500GB 5400RPM hard disk drive. The laptop was equipped with 14.0" diagonal widescreen TFT LCD display at $1366 \times 768$ native resolution with 10-point multi-touch support.

The software instrument was an HTML application consisted of 8 pages, the front page with two buttons, one to move to the identity page, and one to download the previous test result; the identity page where participants or parents will fill out name, age and gender of the participant, and whether participants are grouped into experiment or control group which were assigned by the tester; the training page, which can be found by touching the pretest button in the identity page, consisted of pair of photos with one reference face photo and a group photo of four; and test stages in 4 test pages that can be found by touching the start test button in the identity page.

At each test page there were a pair of photos, one single face photo for reference and one group photo consisted 7, 14, 21, and 28 individuals including the reference faces, depending on the stage. At the end of stage 4 , the participant was shown the end page which consisted of "Thank you" notes and information that the test has been finished. Below, two buttons will be available, one was used to save the result, and one to go back to the front page.

The software recorded the data in a *.csv format consisted of name, gender, age, group, the correct answer for each stage, the answer participant gave for each trials within each stage, and time of answer for each trials within each stage in seconds.

\section{Participants}

Using WhatsApp's Groups, researchers called for participations of adolescents in Yogyakarta. There are 32 non-ASD participants aged 10 to 16 years old recruited, consisted of 22 males and 10 females.

\section{Procedures}

Twenty-eight boys and girls were divided into 4 groups of photos consisted of 7, 14, 
21, and 28 individuals in each of the photos. Each photo is mixed of picture of boys and girls of different ages. These 4 photos will become the stimuli in the software.

\section{Data analysis}

The instrument was analyzed for reliability using the Alpha Cronbach formula.

\section{Study 2: Differentiating ASD from typical adolescents}

Study 2 used experimental method in which a set of 4 paired photos was shown; each paired photo consisted of one single reference photo, and one group photos in which the reference face is included. Participants were then asked to touch the similar face based on the reference photo in the group photo. The test start in stage 1 , with a pair of one male reference photo with 7 individuals in a group photo, followed by stage 2, with one female reference photo with 14 individuals in a group photo, followed by stage 3 , with another male reference photo with 21 individuals in a group photo, and at last, stage 4 , with one female reference photo with 28 individuals in a group photo. In every stage, participants were given 3 trials to find the correct faces, and maximum of 5 minutes for each trial. The test will advance to the next stage even if subject failed all three trials, with the amount of time needed to answer in each trial recorded.

\section{Participants}

The participants for this research were chosen by purposive sampling in which certain criteria were defined beforehand. The experiment group participants for this research came from Forum Komunikasi Orang tua dan Masyarakat Peduli Autis (Communication Forum for Parents and Community Care for Autism) shortly called FORKOMPAK. Through the forum, this study managed to recruit with adolescents diagnosed with ASD by mental health practitioners (psychiatrist or psychologist), proven by showing the medical record of their children. The experimental groups consisted of 24 males, and 7 females with average age of 11.8 years old. They were chosen based on those who were able to communicate at basic level and understand the instruction given to them. The experimental group data were taken at participants' homes to make sure that the participants were comfortable.

The control group participants came from local population, consisted of 10 males and 22 females, with average age of 11.1 years old. The control group must have never been diagnosed with any mental health problems and attend regular school. The control group data were taken in Mind, Brain, and Behavior Laboratory in the Faculty of Psychology, Universitas Gadjah Mada. Both the experimental and the control group took the same instrument of Supra Facial Recognition Test (SFRT).

\section{Procedures}

General procedures. First, participants' parents or guardians were asked to read and signed the informed consent, the content of the consent were information regarding the experiment. After signing the consent, the participants received an explanation about the procedure of the test in front of their parents or guardians, 
followed by filling out identity details by participants, parents or guardians. The pretest run can be repeated as much as necessary until the participants understood the instruction and wanting to start the test. Participants then ran the test until the last stage, after which the tester saved the test record, and stopped the test.

Specific procedures. For the experimental groups, parents or guardians were asked to show their medical record to the tester, before signing the informed consent. Parents or guardians were also asked to accompany the experiment groups participant to help them calm down, as well as to help them understood the instruction during the pre-test run, parents or guardians were not, however be allowed to help the participants test at any stage.

\section{Data analysis}

Since the test result showed the correct answers and the amount of time to answer which were measured on different scales, a score conversion was needed to make sure that both results can be calculated together. First, both the answer and time scores were averaged across three trials to find the average score per stage of test. After that, the average score was converted into a T-score, so that it could be used for comparison sake. Lastly, the T-score for both the correct answers and times from each stage were averaged.

\section{Results}

\section{Study 1}

In study 1 , there were 4 stages, in which photo with 7 pictures is stimulus of stage 1 , with 14 pictures as stimulus stage 2 , and so on. In stage 1 all participants correctly responded to stimulus number 1 . In stage 2 with 14 pictures, 3 participants answered wrongly in the first trial, but all correctly in the second trial. In stage 3 with 21 pictures, 2 participants failed in the first trial, but all were successful in the second trial. In stage 4, 2 participants failed in the first trial but successful in the second trial. In conclusion, the qualitative analysis of 4 stages showed that the software is satisfactory when tested to the non-autistic individuals. In this study, Reliability Analysis using Alpha Cronbach formula, showed that out of 4 stages of test $\alpha=0.803$; as shown in Table 1. Figure 1 shows the front page of the software, and Figure 2 shows the participant's identity page. Stimuli for trial consisted of photos of 4 individuals and 1 designated picture as seen in Appendix A. Appendix B shows the stimulus with 7 pictures.

Table 1.

Reliability Test Result

\begin{tabular}{cc}
\hline $\begin{array}{c}\text { Cronbach's } \\
\text { Alpha }\end{array}$ & N of Items \\
\hline .803 & 4 \\
\hline
\end{tabular}

For further reference, this software is named Supra Face Recognition Test (SFRT) and has been awarded an Intellectual Property Right (IPR) from the Ministry of Law and Human Rights number EC00202000590, dated 7 January 2020.

\section{Study 2.}

In study 2, Multivariate Analysis of Variance (MANOVA) were used to compare the correct answers and time data from experiment and control group. First 
hypothesis was accepted; there was a for correct answers and time needed to significant difference in test result between experiment and control group. Table 2 shows the result of MANOVA for T-score of both the correct answers and time needed to answer between both groups, Wilks' $\lambda=0.739, F(2,60)=10.610, p<0.001$. In it, the result showed that both the score answer between experiment groups and control group significantly differed, and as such the first hypothesis was accepted. Since the first hypothesis was accepted, further analysis was needed to find out whether experimental group performed worse than control.

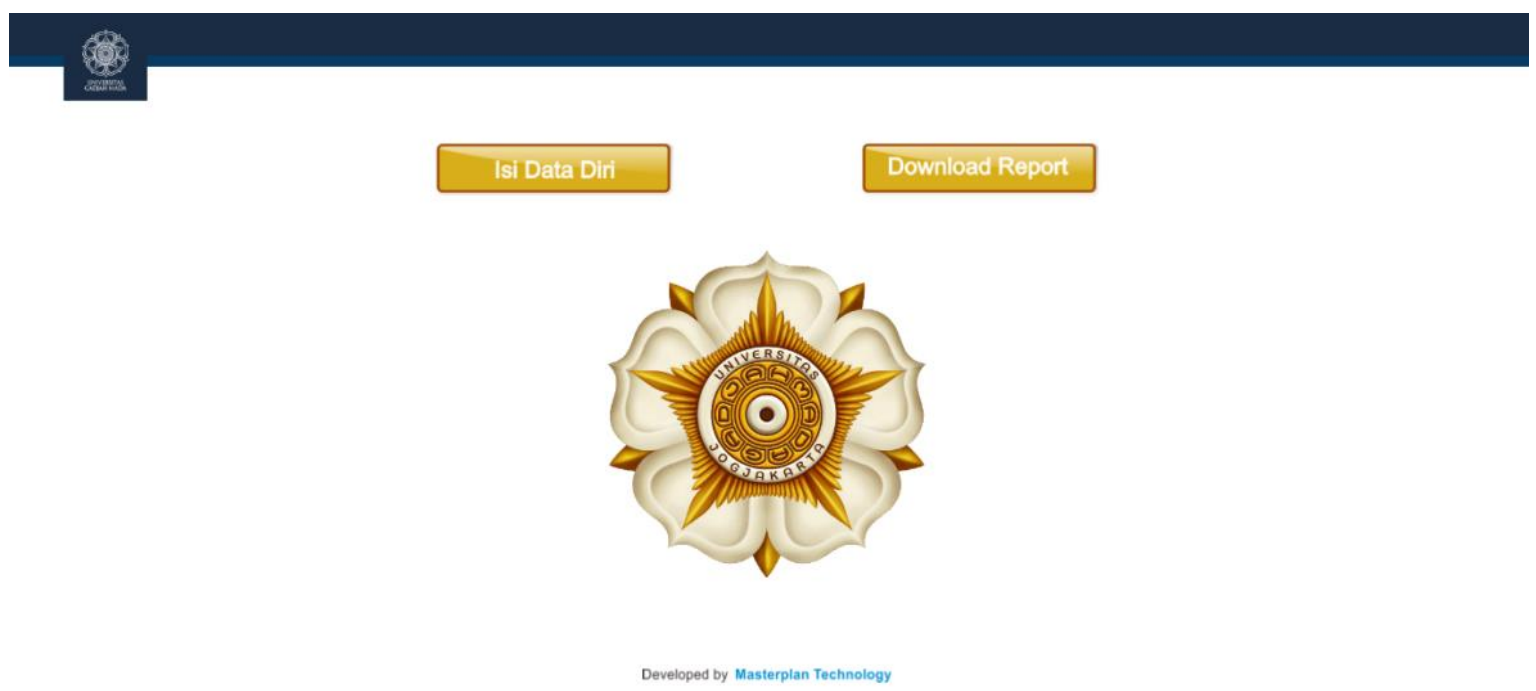

Figure 1. The front page of software

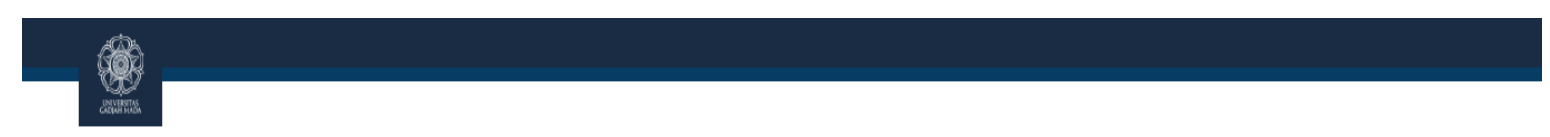

Silahkan Isi Data Diri Peserta Test

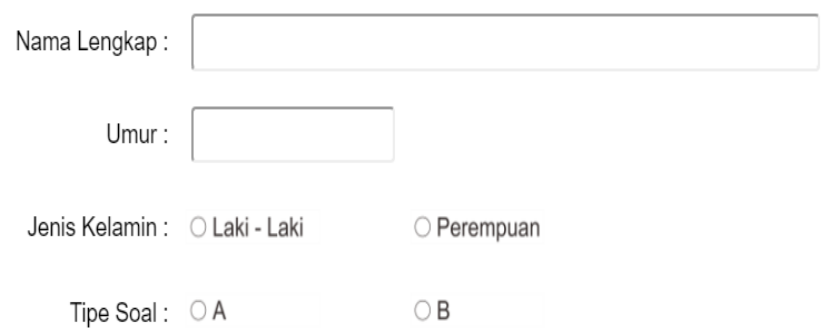

Figure 2. Participant identity page 
Table 2.

Descriptive statistics and results of MANOVA

Descriptive Statistics

\begin{tabular}{clccc}
\hline \multicolumn{1}{c}{ Tipe } & & Mean & Std. Deviation & N \\
\hline \multirow{2}{*}{ Tscore Total } & Normal & 53.5582 & 2.90738 & 32 \\
& Autis & 46.3270 & 9.97500 & 31 \\
& Total & 50.0000 & 8.10260 & 63 \\
\multirow{5}{*}{ Ttime Total } & Normal & 53.6601 & 2.44493 & 32 \\
& Autis & 46.2218 & 8.76096 & 31 \\
& Total & 50.0000 & 7.36067 & 63 \\
\hline
\end{tabular}

Multivariate Test ${ }^{\mathrm{a}}$

\begin{tabular}{|c|c|c|c|c|c|c|c|c|c|}
\hline & Effect & Value & $\mathbf{F}$ & $\begin{array}{l}\text { Hypho- } \\
\text { thesis df }\end{array}$ & $\begin{array}{c}\text { Error } \\
\text { df }\end{array}$ & Sig. & $\begin{array}{c}\text { Partial Eta } \\
\text { Squared }\end{array}$ & $\begin{array}{l}\text { Noncent. } \\
\text { Parameter }\end{array}$ & $\begin{array}{c}\text { Observed } \\
\text { Power }^{c} \\
\end{array}$ \\
\hline \multirow[t]{4}{*}{ Intercept } & Plllal's Trace & .985 & $1931.269^{b}$ & 2.000 & 60.000 & .000 & .985 & 3862.539 & 1.000 \\
\hline & Wilks' Lambda & .015 & $1931.269^{\mathrm{b}}$ & 2.000 & 60.000 & .000 & .985 & 3862.539 & 1.000 \\
\hline & Hotelllng's Trace & 64.376 & $1931.269^{b}$ & 2.000 & 60.000 & .000 & .985 & 3862.539 & 1.000 \\
\hline & Roy's Largest Root & 64.376 & $1931.269^{\mathrm{b}}$ & 2.000 & 60.000 & .000 & .985 & 3862.539 & 1.000 \\
\hline \multirow[t]{4}{*}{ Tipe } & Plllal's Trace & .261 & $10.610^{\mathrm{b}}$ & 2.000 & 60.000 & .000 & .261 & 21.221 & .986 \\
\hline & Wilks' Lambda & .739 & $10.610^{\mathrm{b}}$ & 2.000 & 60.000 & .000 & .261 & 21.221 & .986 \\
\hline & Hotelllng's Trace & 354 & $10.610^{\mathrm{b}}$ & 2.000 & 60.000 & .000 & .261 & 21.221 & .986 \\
\hline & Roy's Largest Root & .354 & $10.610^{\mathrm{b}}$ & 2.000 & 60.000 & .000 & .261 & 21.221 & .986 \\
\hline
\end{tabular}

a. Design: Intercept + Tipe

b. Exact statistic

c. Computed using alpha -.05

Second hypothesis was tested using One Way Analysis of Variance (ANOVA) by comparing the correct answer and average time of experiment with control groups. Means and Upper/Lower Bound data were used to check whether the experiment group performed worse than control as predicted. Table 3 shows the result of the ANOVA for T-score for the correct answer and time needed to answer between both groups. Regarding the correct answers, it was found that experiment group performed significantly worse than the control group with $F(1,61)$ $=15.468 p<0.001$, and an average Mean of 46.3270 compared to 53.5582 for the control group and scores ranging from 42.6681 - 49.9859 compared to 52.5100 54.6064 for the control group. Experiment group also performed significantly worse compared to control group with $F(1,61)=$ $21.360 p<0.001$, and average Mean of 46.2218 compared to 53.6601 in control group, and scores ranging from 43.0083 49.4354 compared to 52.7786 - 54.5416 in control group. Looking at both results, it can be concluded that the second hypothesis was accepted.

\section{Discussion}

The purpose of this research was to take the first step in creating a valid and reliable tool to help with the early detection of autism using face recognition, and for that, it is important first to establish that there is a difference in face recognition ability between children with autism spectrum disorder and typical children. 
Table 3.

Results of ANOVA

Descriptives

\begin{tabular}{|c|c|c|c|c|c|c|c|c|c|c|c|}
\hline & & & \multirow{2}{*}{$\mathbf{N}$} & \multirow{2}{*}{ Mean } & \multirow{2}{*}{$\begin{array}{l}\text { Std. } \\
\text { Devia- } \\
\text { tion }\end{array}$} & \multirow{2}{*}{$\begin{array}{l}\text { Std. } \\
\text { Error }\end{array}$} & \multicolumn{2}{|c|}{$\begin{array}{l}\text { 95\% Confidence } \\
\text { Interval for Mean }\end{array}$} & \multirow{2}{*}{$\begin{array}{l}\text { Mini- } \\
\text { mum }\end{array}$} & \multirow{2}{*}{$\begin{array}{l}\text { Maxi- } \\
\text { mum }\end{array}$} & \multirow{2}{*}{$\begin{array}{c}\text { Between- } \\
\text { Compo- } \\
\text { nent } \\
\text { Variance }\end{array}$} \\
\hline & & & & & & & $\begin{array}{l}\text { Lower } \\
\text { Bound }\end{array}$ & $\begin{array}{l}\text { Upper } \\
\text { Bound }\end{array}$ & & & \\
\hline \multirow{5}{*}{$\begin{array}{l}\text { TScore } \\
\text { Total }\end{array}$} & Normal & & 32 & 53.5582 & 2.90738 & .51396 & 52.5100 & 54.6064 & 42.92 & 55.34 & \\
\hline & Autis & & 31 & 46.3270 & 9.97500 & 1.79156 & 42.6681 & 49.9859 & 22.49 & 55.34 & \\
\hline & Total & & 63 & 50.0000 & 8.10260 & 1.02083 & 47.9594 & 52.0406 & 22.49 & 55.34 & \\
\hline & Model & $\begin{array}{l}\text { Fixed } \\
\text { Effects }\end{array}$ & & & 7.29592 & .91920 & 48.1619 & 51.8381 & & & \\
\hline & & $\begin{array}{l}\text { Random } \\
\text { Effects }\end{array}$ & & & & 3.61601 & 4.0542 & 95.9458 & & & 24.45505 \\
\hline \multirow{5}{*}{$\begin{array}{l}\text { TTime } \\
\text { Total }\end{array}$} & Normal & & 32 & 53.6601 & 2.44493 & .43221 & 52.7786 & 54.5416 & 44.58 & 55.92 & \\
\hline & Autis & & 31 & 46.2218 & 8.76096 & 1.57352 & 43.0083 & 49.4354 & 19.74 & 54.95 & \\
\hline & Total & & 63 & 50.0000 & 7.36067 & .92736 & 48.1462 & 51.8538 & 19.74 & 55.92 & \\
\hline & Model & $\begin{array}{l}\text { Fixed } \\
\text { Effects }\end{array}$ & & & 6.38639 & .80461 & 48.3911 & 51.6089 & & & \\
\hline & & $\begin{array}{l}\text { Random } \\
\text { Effects }\end{array}$ & & & & 3.71954 & 2.7387 & 97.2613 & & & 26.36857 \\
\hline
\end{tabular}

\begin{tabular}{llrrrrr} 
ANOVA & & & & & \\
\hline & & Sum of Squares & df & Mean Square & F & Sig. \\
\hline TScore Total & Between Groups & 623.371 & 1 & 823.371 & 15.468 & \\
& Within Groups & 3247.057 & 61 & 53.230 & & .000 \\
& Total & 4070.427 & 62 & & & \\
\multirow{2}{*}{ TTime Total } & Between Groups & 871.187 & 1 & 871.187 & 21.360 & .000 \\
& Within Groups & 2487.942 & 61 & 40.786 & & \\
\hline
\end{tabular}

The finding of this research showed that there is a difference in face recognition ability between children with ASD and typical children as shown in the number of correct answers of similar faces and the time needed to answer them. This finding is consistent with previous findings regarding this topic, for example: the result of Apicella et al. (2013), Grelotti et al. (2005), Pierce and Redcay (2008) and Tang et al. (2015).

It was also important to understand that the underlying mechanism for the worse performance is still not yet clear. Most studies in this matter are still showing conflicting conclusions whether there is an underlying neurological cause for such performance (Carver \& Dawson, 2002; Courchesne, 2003; Herbert et al., 2003) or is it simply a matter of interest and attention (Grelotti et al., 2005; Pierce \& Redcay, 2008). Whether or not there is an underlying neurological cause for worse performance in face recognition task, the current result showed that there is a significant difference in the result of adolescents with autism compared to typical adolescents and as such further investigation into this topic should be encouraged.

The current finding also shows some issues that should be addressed in the future, such as the gender and geographical factors, as some findings shows that 
there are significantly higher prevalence of autism in male versus female (Connellan et al., 2000), and urban versus rural areas (Lai, Tseng, Hou, \& Guo, 2012). Also, since the face recognition test was designed for the purpose of usage in primary mental health facilities, it was designed to be quick-test that can be done in short amount of time rather than trying to get finer detail of face recognition ability of participants. As such, future research should try to create a finer tool, for example, by increasing the number of face stimuli in the test and/or reducing the interval between one stage and the next. The current research also focused solely on the participant input, and as such there were many possibilities of disturbances that might affect the result.

\section{Conclusions}

As stated in the aim of this research which was to find a practical, suitable, yet scientific tool for early diagnosis of ASD particularly in the public health center setting, it is found that the software which is called Supra Face Recognition Test (SFRT) is suitable and appropriate. The software is also sensitive to detect adolescents with ASD from those of typical adolescents.

\section{Suggestions}

Public Health Center practitioners, and institution of education for psychologist can use this tool to help them diagnose the disorder.

\section{Acknowledgement}

The authors wish to thank all the ASD adolescents and the family who participated in this study, and also Komunikasi Orang tua dan
Masyarakat Peduli Autis (Communication Forum for Parents and Communities Care for Autism) shortly called FORKOMPAK for allowing their members to participate in the study. Lastly, the authors also thank to all boys and girls from Yogyakarta community who participated in this study.

\section{Authors' contributions}

Supra Wimbarti designed the study, analyzed the data, and writing the report. Willy Kristianto Yappy designing the software, collecting the data, and writing the report.

\section{Conflict of interest}

The authors declare there is not conflict of interest in this research.

\section{Orcid id}

Supra Wimbarti: https://orcid.org/0000-00032821-2403

\section{References}

American Psychiatric Association (Ed.). (2013). Diagnostic and statistical manual of mental disorders: DSM-5 (5th ed). Washington, D.C: American Psychiatric Association.

Anggraeni, R. (2017, July). Waspada! anak autis bisa alami gangguan jiwa [News]. Retrieved from https://lifestyle.sindonews.com/read/1 220611/155/waspada-anak-autis-bisaalami-gangguan-jiwa-1500006434 March 21, 2018.

Apicella, F., Sicca, F., Federico, R. R., Campatelli, G., \& Muratori, F. (2013). Fusiform Gyrus responses to neutral and emotional faces in children with Autism Spectrum Disorders: a High Density ERP study. Behavioural Brain Research, 251, 155-162. doi: 10.1016/j.bbr.2012.10.040 
Carver, L. J., \& Dawson, G. (2002). Development and neural bases of face recognition in autism. Molecular Psychiatry, 7(S2), S18-S20. doi: 10.1038/sj.mp.4001168

Connellan, J., Baron-Cohen, S., Wheelwright, S., Batki, A., \& Ahluwalia, J. (2000). Sex differences in human neonatal social perception. Infant Behavior and Development, 23(1), 113-118. doi: 10.1016/S01636383(00)00032-1

Courchesne, E. (2003). Evidence of brain overgrowth in the first year of life in autism. JAMA, 290(3), 337. doi: 10.1001/jama.290.3.337

Ehlers, S., Gillberg, C., \& Wing, L. (1999). A screening questionnaire for asperger syndrome and other high-functioning autism spectrum disorders in school age children. Journal of Autism and Developmental Disorders, 29(2), 14.

Golarai, G., Grill-Spector, K., \& Reiss, A. L. (2006). Autism and the development of face processing. Clinical Neuroscience Research, 6(3), 145-160. doi: $10.1016 /$ j.cnr.2006.08.001

Grelotti, D. J., Klin, A. J., Gauthier, I., Skudlarski, P., Cohen, D. J., Gore, J. C., ... Schultz, R. T. (2005). fMRI activation of the fusiform gyrus and amygdala to cartoon characters but not to faces in a boy with autism. Neuropsychologia, 43(3), 373-385. doi: 10.1016/j.neuropsychologia.2004.06.01 5

Herbert, M. R., Ziegler, D. A., Deutsch, C. K., O'Brien, L. M., Lange, N., Bakardjiev, A., ... Caviness, V. S. (2003). Dissociations of cerebral cortex, subcortical and cerebral white matter volumes in autistic boys. Brain, 126(5), 1182-1192. doi: $\underline{10.1093 / \text { brain/awg110 }}$
Joseph, R. M., \& Tanaka, J. (2003). Holistic and part-based face recognition in children with autism. Journal of Child Psychology and Psychiatry, 44(4), 529542.

Kleinman, J. M., Robins, D. L., Ventola, P. E., Pandey, J., Boorstein, H. C., Esser, E. L., ... Fein, D. (2008). The modified checklist for autism in toddlers: a follow-up study investigating the early detection of autism spectrum disorders. Journal of Autism and Developmental Disorders, 38(5), 827839. doi: $10.1007 /$ s10803-007-0450-9

Lai, D.-C., Tseng, Y.-C., Hou, Y.-M., \& Guo, H.-R. (2012). Gender and geographic differences in the prevalence of autism spectrum disorders in children: Analysis of data from the national disability registry of Taiwan. Research in Developmental Disabilities, 33(3), 909915. doi: $10.1016 / j . r i d d .2011 .12 .015$

Manafe, D. (2018, July). Kesehatan jiwa di Indonesia masih terabaikan. Retrieved from

https://www.beritasatu.com/nasional/ 502826-kesehatan-jiwa-di-indonesiamasih-terabaikan.html, January 19, 2019.

Lestari, M. R. D. (2016, October). Netralnews.com - Belum semua provinsi memiliki rumah sakit jiwa. Retrieved from http://www.netralnews.com/news/kes ehatan/read/30282/belum-semuaprovinsi-memiliki-rumah-sakit-jiwa, January 19, 2019.

Pierce, K., \& Redcay, E. (2008). Fusiform function in children with an autism spectrum disorder is a matter of "Who." Biological Psychiatry, 64(7), 552-560. doi: 10.1016/j.biopsych.2008.05.013. 
Russell, R., Sinha, P., Biederman, I., \& Nederhouser, M. (2006). Is pigmentation important for face recognition? Evidence from contrast negation. Perception, 35(6), 749-759. doi: $\underline{10.1068 / p 5490}$

Schopler, E., Van Bourgondien, M. E., Wellman, G. J., \& Love, S. R. (2010). Childhood autism rating scale, second edition (Manual). Torrance, CA: Western Psychological Services. Retrieved from http://www.childhealthcare.org/ug/C ARS/CARS2_manual.pdf

Tanaka, J. W., Kiefer, M., \& Bukach, C. M. (2004). A holistic account of the ownrace effect in face recognition: evidence from a cross-cultural study. Cognition, 93(1), B1-B9. doi: 10.1016/j.cognition.2003.09.011

Tang, J., Falkmer, M., Horlin, C., Tan, T., Vaz, S., \& Falkmer, T. (2015). Face recognition and visual search strategies in autism spectrum disorders: Amending and extending a recent review by Weigelt et al. PLOS ONE, 10(8), e0134439. doi: 10.1371/journal.pone.0134439

van Kooten, I. A. J., Palmen, S. J. M. C., von Cappeln, P., Steinbusch, H. W. M., Korr, H., Heinsen, H., ... Schmitz, C. (2008). Neurons in the fusiform gyrus are fewer and smaller in autism. Brain, 131(4), 987-999.

doi: 10.1093/brain/awn033

Zhang, J., Li, X., Song, Y., \& Liu, J. (2012). The fusiform face area is engaged in holistic, not parts-based, representation of faces. PLoS ONE, 7(7), e40390. doi: 10.1371/journal.pone.0040390. 


\section{Appendix A}

Example of Stimuli Used to Train the Participants in using the Software
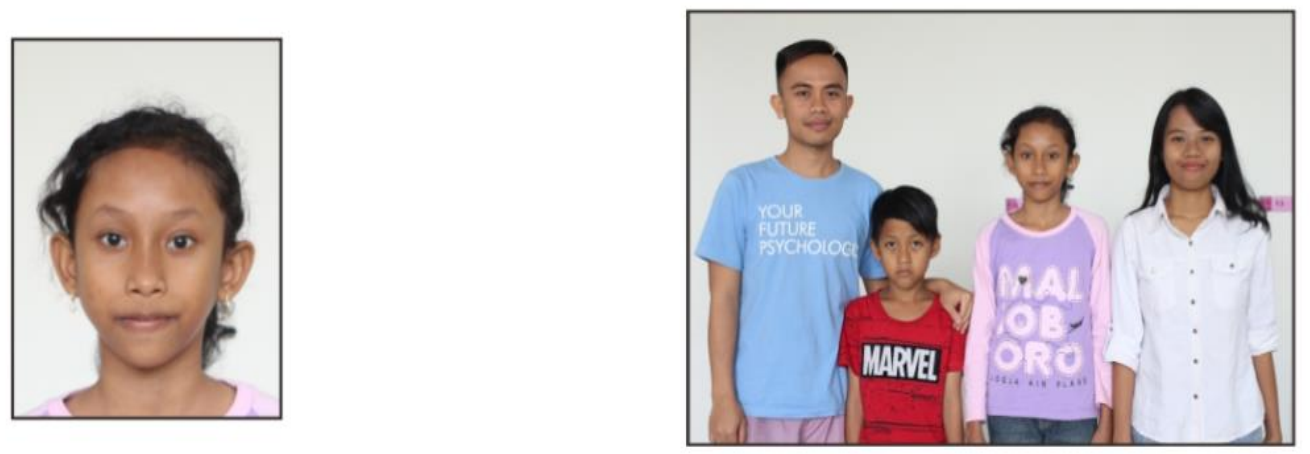

\section{Appendix B}

The First Picture Consisted of 7 Individuals

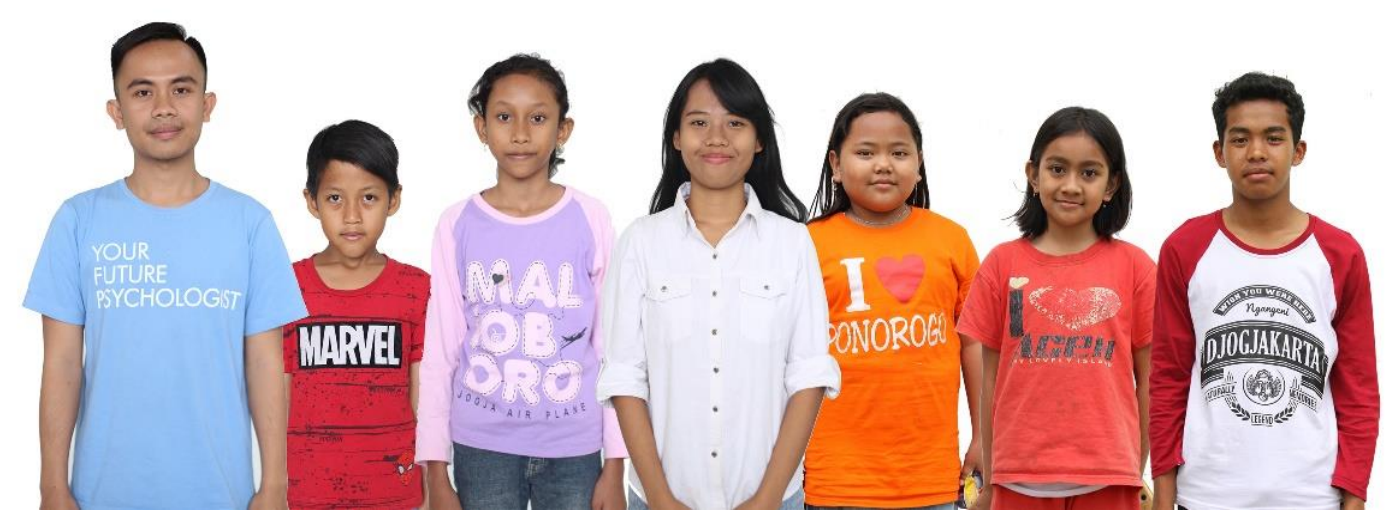

